\title{
PEIRCE EN ESPAÑA Y ESPAÑA EN PEIRCE*
}

\author{
Jaime Nubiola
}

(Universidad de Navarra)

El objeto de estas páginas es dar noticia de la visita de Charles Sanders Peirce a España en 1870, de su presencia en la bibliografía española a través de traducciones y de las referencias a España que ocasionalmente aparecen en sus escritos.

\section{VIAJE A ESPAÑA}

La única información publicada hasta el momento del viaje de Charles S. Peirce a España se debe a Max H. Fisch, el más profundo conocedor de la biografía del lógico y científico norteamericano (1981: 13-14; 1982: 124; 1984: xxxiv), y a su discípulo Christian J. W. Kloesel, direc-

* Debo gratitud a Christian J. W. Kloesel por su orientación, a Nathan Houser por las transcripciones de la Max H. Fisch Library, y a Melanie Wisner por las copias de los manuscritos de Peirce (L 254 y L 341) que cito con permiso de la Houghton Library. 
tor del Peirce Edition Project (1990: 4-7). Las circunstancias de aquel viaje ponen de manifiesto la multiplicidad de los intereses de Charles S. Peirce.

En 1861 - contaba entonces Peirce con veintiún años-- entró a trabajar como ayudante de su padre Benjamin en el U. S. Coast and Geodetic Survey, el principal organismo científico del Gobierno americano en aquella época, mientras completaba sus estudios e iniciaba su carrera docente en Harvard. En 1869 formó parte de uno de los equipos que estudiaron en Kentucky el eclipse total de sol del 7 de agosto. La observación mediante el telescopio de la corona solar y sus protuberancias y la detección de helio con el espectroscopio llevaron a los astrónomos americanos a formular nuevas teorías sobre la composición del sol que fueron recibidas con cierto escepticismo entre los astrónomos europeos.

Como no iba a haber otra ocasión tan favorable en el siglo XIX, Benjamin Peirce, superintendente entonces de la Coast Survey, obtuvo una dotación del Congreso para organizar una expedición de observación para el siguiente eclipse que habría de tener lugar al mediodía del 22 de diciembre de 1870 sobre el Mediterráneo. Para garantizar el éxito del proyecto envió a Europa a su hijo Charles con seis meses de antelación para que organizara los preparativos. Pasó por Londres, Rotterdam, Berlín, Praga, Viena, Pest y llegó a Constantinopla, para recorrer luego de Este a Oeste la zona de totalidad del eclipse en busca de emplazamientos adecuados como observatorios. En Italia seleccionó algunos asentamientos en Sicilia y el 28 de octubre abandonaba Florencia para iniciar la que calificó como su correría española («Spanish hurry-skurry»).

Los datos que disponemos de la estancia de Peirce en España son escasos por ahora: se trata de un viaje muy rápido, pues el 15 de noviembre se encuentra ya en Grenoble. Probablemente llega por barco al sur de Andalucía, quizá a Gibraltar. Acude a Jerez, en donde encuentra un emplazamiento que estima satisfactorio para la observación del eclipse. A continuación, viaja a Granada, en donde queda impresionado por la Alhambra, que visita acompañado de un anciano guía que habla muy bien inglés. En 1898 - casi treinta años después-, comparará las hipótesis matemáticas con la decoración de la Alhambra: son inferiores, pero se asemejan en que son «tan hermosas como sin alma». En Granada se aloja en el Hotel Siete Suelos, en donde es estafado, pues le pasan a sabiendas moneda falsa. Por este motivo, cuando escribe Peirce el 29 de noviembre al Prof. Winlock, le recomienda que se aloje en el Hotel Washington Irving. En esta ciudad ve cómo un artista francés adquiere un manuscrito bajomedieval de textos de la Escritura a un precio irrisorio (125\$), mientras que estima podría venderse en Londres por 700 dólares.

El día 12 de noviembre de 1870 está en Madrid, según consta en el pasaporte expedido a Peirce en la legación de los Estados Unidos. Muy 
probablemente, hace en tren la totalidad del viaje por España, pues tanto Jerez como Granada, Madrid e Irún están ya unidas por la red de ferrocarriles. El paso por Irún es una conjetura muy probable, pues cuando enumera las dieciocho lenguas diferentes que ha oído hablar a lo largo de su viaje -diecisiete de ellas en territorios donde eran el modo de hablar habitual-, es precisamente el vascuence la última que menciona. De todas maneras, Peirce no sabía español y de poco se enteraría, pues añade: «Los españoles hablan como si tuvieran piedras en la boca, lo que hace muy difícil captar la distinción de sus sonidos» (L 341).

En carta de 16 de noviembre cuenta además a su madre lo mucho que le ha gustado una estatua de un artista de la época (se trata probablemente de La ninfa Eurídice de Sabino Medina); describe las tres compras que ha hecho: una manta con bordados gitanos para calentarse en los viajes, un abanico de madreperla y una docena de fotografías de los mejores cuadros que ha visto en Madrid; califica nuestro país como maravilloso para obtener antigüedades raras y describe los dos hermosos manuscritos miniados que ha visto adquirir a bajo precio.

De hecho, Charles S. Peirce se unió al grupo de científicos americanos —entre los que se encontraba su esposa Zina y su padre Benjamin-que siguieron el eclipse en las cercanías de Catania (Sicilia), aunque, sin embargo, su espectroscopio fue enviado por error a Jerez, donde estaba el segundo grupo del U.S. Coast Survey. Este grupo, dirigido por el Prof. Joseph Winlock, director del Observatorio de Harvard, estaba formado por once americanos, dos ingleses y un observador español que se les unió. Contaron con la colaboración del capitán Pujazón, director del Observatorio de San Fernando (Cádiz). El emplazamiento principal se situó en un olivar, a una milla al nordeste de Jerez. A pesar de que salió un día nublado y con alguna lluvia, las observaciones del 22 de diciembre de las dos expediciones tuvieron éxito y confirmaron las conclusiones obtenidas por los americanos a raíz del eclipse anterior. Después de aquel breve viaje exploratorio, Peirce no volvió de nuevo a nuestro país.

\section{TRADUCCIONES AL ESPAÑOL}

La primera traducción de Peirce al castellano es muy temprana: se trata de un artículo breve, «Irregularidades en las oscilaciones del péndulo», que publica la revista Crónica Científica el 25 de octubre de 1883, traduciendo las observaciones de Peirce publicadas el año precedente en The American Journal of Science. 
La segunda referencia a Peirce en la bibliografía española es el artículo de Ventura Reyes Prósper, publicado en 1892 en El Progreso matemático de Zaragoza, en el que este singular matemático reseña los trabajos lógico-matemáticos de Peirce -con quien había tenido correspondencia-y le ofrece, « con las excusas por los errores en que haya incurrido, un testimonio de admiración sincera que desde el otro lado de los mares le envía un extranjero» (1892: 173). Sin embargo, en el ámbito de la filosofía profesional es preciso esperar hasta 1933 para hallar la primera mención: se trata de una breve exposición de la lógica de Peirce que ofrece Juan David García Bacca en la entrada «Simbólica (Lógica)» del Apéndice a la Enciclopedia Espasa, en la que resumía la información proporcionada por el libro de C. I. Lewis A Survey of Symbolic Logic de 1918 (Muñoz 1980: 909-911).

La primera edición castellana de Peirce ha de esperar a las dos breves traducciones de Juan Martín Ruiz-Werner publicadas por Aguilar Argentina en Buenos Aires: Deducción, inducción e hipótesis: 1970, 90 págs. y Mi alegato en favor del pragmatismo. 1971, 91 págs., a las que sigue la de B. Bugni, La ciencia de la semiótica. Buenos Aires: Nueva Visión, 1974, 116 págs.

Un alcance mayor tiene la traducción de Dalmacio Negro de Lectures on Pragmatism de 1903 - bajo el título Lecciones sobre el pragmatismo, Buenos Aires: Aguilar, 1978, 275 págs.-, que se encuadra dentro de un proyecto -que no prosperó- de traducción de los ocho volúmenes de los Collected Papers de Peirce.

En los últimos años han visto la luz tres traducciones españolas que hacen más asequible una parte relevante de la vasta producción peirceana. Se trata de la edición de Armando Sercovich Obra lógico-semiótica. Madrid: Taurus, 1987, 431 págs., que compila —traducidos por R. Alcalde y M. Prelooker- algunos escritos de Peirce sobre semiótica, diez cartas a Lady Welby en las que Peirce explicaba la teoría del signo, y diez secciones de los Collected Papers sobre estas materias; la traducción de Pilar Castrillo Criado bajo el título Escritos lógicos, Madrid: Alianza, 1988, 264 págs., en la que reúne once trabajos de Peirce representativos de sus aportaciones en Lógica; y la edición de José Vericat titulada El hombre, un signo (El pragmatismo de Peirce). Barcelona: Crítica, 1988, 428 págs., que cuenta con una introducción y abundantes notas e información bibliográfica.

Para completar esta referencia bibliográfica peirceana, cabe mencionar la traducción de algunas páginas de «Some Amazing Games» sobre trucos de cartas con fundamento matemático, en Investigación y Ciencia, 24 (1978: 104-106); la traducción de José Miguel Gambra del libro de Pierre Thibaud La logique de Charles Sanders Peirce (Madrid: Paraninfo, 1982) y la única monografía sobre Peirce producida hasta 
ahora en nuestro país: Hacia una Semiótica Pragmática. El signo en Ch. S. Peirce, de Antonio Tordera, publicada en 1978 en Valencia, bajo el sello editorial, ya desaparecido, Fernando Torres Editor.

El creciente interés en nuestro país por la obra peirceana (Castañares 1985, 1990; Pérez Carreño 1988; Pérez de Tudela 1988) se debe, más que a estas traducciones, al influjo de Umberto Eco y de Karl-Otto Apel y a la progresiva aproximación en los últimos años de la filosofía española a la filosofía académica norteamericana. Ambos factores han sido decisivos —en mi opinión - para advertir que Charles Sanders Peirce era o, mejor, es importante para una cabal comprensión de la cultura contemporánea.

\section{REFERENCIAS ESPAÑOLAS}

Alemania, Escocia, Inglaterra, Francia y, quizá en menor medida, Italia son los países europeos que más frecuentemente aparecen mencionados en los escritos de Peirce. Las referencias a España - en consonancia con el escaso papel de nuestro país en la comunidad científica y cultura europea del último cuarto del siglo xIX - son muy raras.

De conformidad con su condición profesional de lógico, la cita española más frecuente - en una veintena de lugares de los Collected Papers y de los cuatro volúmenes publicados hasta el momento de la Chronological Edition - es la de Pedro Hispano (h. 1226-1277), «la más alta autoridad en terminología lógica» (CP, 2.323n). Para Peirce se trata de «un noble portugués» a causa de su muy probable nacimiento en Lisboa, y sus famosas Simmulae logicales, que quizá escribiera en Astorga y que pervivieron como manual de Lógica hasta principios del siglo XVII, son citadas por él abundantemente: «Si [Pedro Hispano] hubiera vivido más tiempo seguramente habría sido contado entre los más grandes hombres del mundo» $(\mathrm{CP}, 4.26)$.

En un segundo lugar Peirce menciona a Raimundo Lulio (1233-1316), «uno de los lógicos más perspicaces» (CP, 4.465), si bien descalifica como «nonsensical» su Ars magna, y a Juan Luis Vives (1492-1540), a quien reconoce como un notable precedente de los diagramas lógicos de Euler (CP, 4.353, 2.390). Se refiere a Séneca en dos ocasiones, a la definición de número abstracto de Isidoro de Sevilla (CP, 2.428) y a la posición del teólogo Suárez sobre la unión de alma y cuerpo (CP, 6.362).

Quizá refleja bien esta casi total ausencia de España en el horizonte cultural de Peirce el que la única mención directa de nuestro país que he 
encontrado en sus Collected Papers sea la del galicismo «construir castillos en España», en un artículo de 1908, cuando explica su noción de «Musement». Se trata de la especulación libre e irreprimida en la que la mente se divierte sin propósito definido alguno, en puro juego con las ideas: «esta particular ocupación - dice Peirce- puede tomar la forma de contemplación estética, la de construir distantes castillos (sea en España o en la ejercitación moral de uno mismo)...» (CP, 6.458).

En las colaboraciones de Peirce en The Nation hay también algunas referencias españolas, pero de escaso interés, salvo para reflejar que España es a ojos de Peirce un país ignorante (CTN 1: 47). Sin embargo, España está bien presente en el horizonte político y comercial de la vida norteamericana de la época. Por ejemplo, el propio Peirce escribe en The Nation, en diciembre de 1884, dos cartas discutiendo el «tratado de reciprocidad» entre Estados Unidos y España de febrero de aquel año, que regulaba las importaciones de azúcar cubano y portorriqueño (CTN 1:6567). Como es bien conocido, la situación acabará desembocando en la guerra entre España y los Estados Unidos. Con esa ocasión, Peirce escribe a Henry Cabot Lodge ofreciendo su colaboración en la guerra, mediante una máquina por él inventada para cifrar y descifrar mensajes, y augura en su carta que los españoles apenas ofrecerán resistencia en la guerra: «los he estudiado en España; es un pueblo corrompido por los siglos de crueldad, injusticia y rapiña a que se han dado, y les ha quedado poca hombría efectiva» (L 254).

Un dato sorprendente al lector hispano es el hecho de que en los últimos años de su vida Peirce adoptara el nombre castellano de «Santiago», en lugar de «Sanders», como homenaje a su gran amigo y benefactor William James (Weiss 1934: 400).

Seguramente se encontrarán más referencias españolas en Charles Sanders Peirce, pero de lo expuesto se deduce con claridad que Peirce y España corresponden a dos mundos bien diferentes que sólo desde muy cercanas fechas empiezan a confluir, como muestran el número monográfico sobre Peirce de Estudios Semióticos (6-7/1986) y en particular la reciente celebración en julio de 1991 en Segovia de un Seminario Internacional de Literatura y Semiótica bajo el título general ${ } \mathrm{Ch}$. S. Peirce y la Literatura».

\section{Referencias bibliográficas}

CAstañares, W. (1985): El signo: problemas semióticos y filosóficos. Madrid: Universidad Complutense, Tesis doctoral. 
- (1990): «Interpretant and subject: Semiotics or hermeneutics?» Semiotica 81, 193 202.

Fisch, M. H. (1981): «Peirce as Scientist, Mathematician, Historian, Logician and Philosopher». En Proceedings of the C. S. Peirce Bicentennial International Congress, K. L. Ketner et al (eds.), 13-34. Lubbock: Texas Tech Press.

- (1982): «The range of Peirce's relevace (Part II)». The Monist 63, 123-141.

- (1984): «The Decisive Year and Its Early Consequences». En Writings of Charles $S$. Peirce, 2 (1867-1871), E. C. Moore et al (eds.), xxi-xxxvi.

GARCÍA BACCA, J. D. (1933): «Simbólica (Lógica)». En Enciclopedia Universal Ilustrada Europeo-Americana. Apéndice, IX, 1326-1339. Madrid: Espasa-Calpe.

KLOESEL, CH. J. W. (1990): «Scattered Remarks on Peirce an Italy». Versus 55-56, 3-12.

LEwIS, C. I. (1918): A Survey of Symbolic Logic. Berkeley: University of California Press.

MuÑoz Delgado, V. (1980): «Notas para la historia de la lógica durante la Segunda República Española (1931-1939)». Religión y Cultura 26, 893-931.

PeirCe, Ch. S. (1931-1958): Collected Papers, vols. 1-8, C. Hartshorne, P. Weiss y A. W.Burks (eds.). Cambridge, Mass.: Harvard University Press [como es habitual se cita como CP seguido del número de volumen y el del parágrafo].

- (1975-1979): Contributions to 'The Nation' vols. 1-3, K. L. Ketner y J. E. Cook (eds.). Lubbock: Texas Tech Press. [CTN].

- (1982-1989): Writings of Charles S. Peirce: A Chronological Edition, vols. 1-4, M. H. Fisch et al (eds.). Bloomington: Indiana University Press.

Pérez CARReño, F. (1988): Los placeres del parecido. Icono y representación. Madrid: Visor.

PÉREZ DE TUDELA, J. (1988): El pragmatismo americano: Acción racional y reconstrucción del sentido. Madrid: Cincel.

Reyes ProsPer, V. (1982): «Charles Santiago Peirce y Oscar Howard Mitchell». El progreso matemático 2, 170-173.

Weiss, P. (1934): «Charles Sanders Peirce». En Dictionary of American Biography, D. Malone (ed.), XIII, 398-403. New York: Charles Scribner's Sons. 